\title{
Модифицирование поверхности адсорбента для очистки воды ионами алюминия и серебра
}

\author{
Котельникова Т.А. \\ Московский государственный университет им. М.В. Ломоносова, Москва
}

Поступила в редакцию 24.08.2017 г.

\begin{abstract}
Изучено влияние модифицирования поверхности однородно широкопористого силохрома ионами алюминия и серебра на сорбцию веществ - примесей и моделирующих примеси в питьевой воде. Методом нелинейной газовой хроматографии изучена сорбция предельных и ароматических углеводородов, их хлор- и кислородсодержащих производных, аминов. Показано, что модифицирование поверхности кремнеземных сорбентов катионами серебра увеличивает гидрофильность поверхности и сорбцию полярных веществ. Модифицирование поверхности силохрома ионами алюминия увеличивает сорбцию как полярных, так и неполярных веществ многократно, практически не изменяя структурных характеристик адсорбента.

Ключевые слова: адсорбция, адсорбенты, очистка воды, примеси, модифицирование, ионы алюминия и серебра, газовая хроматография.

\section{Surface modification of the adsorbent for the purification of water by ions of aluminium and silver}

\author{
Kotel'nikova T.A. \\ The Moscow state university it. M.V.Lomonosov, Moscow
}

Based on industrial chemically pure homogeneous and widely porous silica C-120, by modifying its surface with cations of aluminum and silver, adsorbents with a high adsorption potential to a number of possible impurities in drinking water have been created. Adsorption properties were studied by the method of nonlinear gas chromatography, which makes it possible to describe an inhomogeneous sorption field. Adsorption of n-hexane, benzene, chlorobenzene, cumene, chloroform, carbon tetrachloride, alcohols, water, tetrachloramine was studied on the initial and modified adsorbents. The obtained materials were compared with silochrome modified with silver nanoparticles, sample C-3,2- $\mathrm{Ag}^{0}$, and activated coconut coal AU used in the Barrier cartridges. Aluminum was applied by impregnating silochrome with a solution of aluminum nitrate nanohydrate and subsequent thermolysis at $200^{\circ} \mathrm{C}$, a sample of C-Al. Aluminosilicate proton-donor and electron-withdrawing strong-acid centers of Brensted and Lewis, capable of very strong adsorption interactions, appear on the surface of silica, and the size of its surface, pore volume and diameter practically do not decrease, remaining available for sorption of large molecules of surfactants, proteins and microorganisms. The $\mathrm{C}$-Al adsorbent grafted on the surface with aluminosilicate centers (concentration $\sim 2 \mathrm{mkmol} / \mathrm{g}$ ) exhibits an adsorption potential with respect to both specifically and nonspecifically sorbed substances, much greater than that for $\mathrm{AU}$ and $\mathrm{C}-3,2-\mathrm{Ag}^{0}$. Silver was applied to $\mathrm{C}-120$ and $\mathrm{C}-\mathrm{Al}$ by ion exchange from a solution of silver nitrate, samples of C-Ag+ and C-Al-Ag+. In both cases, the hydrophilicity and sorption capacity of alcohols, acetone, and other specifically sorbed substances were increased. In this case, the effect of modifying the surface of $\mathrm{C}-120$ with silver cations, a sample of $\mathrm{C}-\mathrm{Ag}+$, is comparable in strength to the effect of modifying silica by metal nanoparticles, $\mathrm{C}-3,2-\mathrm{Ag}^{0}$. The $\mathrm{C}-\mathrm{Al}-\mathrm{Ag}+$ adsorbent exhibits somewhat greater hydrophilicity than $\mathrm{C}$-Al, but the adsorption potential with respect to nonspecifically sorbed substances still remains at a very high level, exceeding that of $\mathrm{AU}$ and other silicas. Amines that model proteins, peptides, some viruses, on $\mathrm{C}-\mathrm{Ag}+, \mathrm{C}-\mathrm{Al}$ and $\mathrm{C}-\mathrm{Al}-\mathrm{Ag}+$ are sorbed irreversibly even at $180^{\circ} \mathrm{C}$. Thus, silica 
modified with cations of aluminum and silver, according to gas chromatography, can be effective as an adsorbent for purifying drinking water and is a promising alternative to activated carbons.

Keywords: adsorption, adsorbents, water purification, impurities, modification, ions of aluminum and silver, gas chromatography.

\section{Введение}

Проблема очистки питьевой воды с течением времени становится всё более острой, прежде всего, по причине огромного диапазона возможных примесей - от ионов до микроорганизмов. Эту проблему часто решают с использованием адсорбентов, и наиболее широкое применение при этом традиционно находят активированные угли (АУ) прежде всего ввиду их коммерческой доступности. Для придания углям бактериостатических свойств их модифицируют наночастицами серебра, которые смываются током очищаемой воды, создавая многократное превышение ПДК $(0,05 \mathrm{mг} / л)$, в то время как примеси серебра присвоен класс опасности 2 , высоко опасный [1]. Кроме того, серебро, находясь в химически активной форме наночастицы, при хранении и в процессе эксплуатации частично окисляется и за счет гидролиза $\mathrm{Ag}_{2} \mathrm{O}[2,3]$ повышает ее щелочность. Эффективность использования активированных углей для очистки воды от микроорганизмов, вирусов, поверхностно-активных веществ (ПАВ), белков, пептидов и др. ограничивает то обстоятельство, что угли неоднородно пористые адсорбенты, и основная часть поверхности (>90\%) приходится на тонкие поры, недоступные для их сорбции [2-5]. Промышленные кремнеземные адсорбенты, силикагели, алюмосиликаты, цеолиты и т.д., для удаления этих примесей также малоэффективны из-за тонко- и неоднородно пористости, и их чаще всего применяют для очистки и осушки газовых потоков и удаления катионов тяжелых металлов. В [6] предложен способ обеззараживания воды с использованием сорбционного фильтра с осажденной в сорбент малорастворимой солью серебра.

Цель работы - создание однородно - широкопористого адсорбента с высоким адсорбционным потенциалом по отношению к веществам, способным как специфическим, так и неспецифическим взаимодействиям [7] и серебром, иммобилизованным на поверхности.

\section{Эксперимент}

Для создания адсорбента с заданными свойствами использовали модифицирование поверхности химически чистого пиролитического однородно широкопористого промышленного силохрома марки C-120 [5] катионами алюминия и серебра. Структурные характеристики C-120: средний диаметр пор, $d=200-300 \AA$, суммарный объем пор $\mathrm{v}_{\Sigma}=1.2 \mathrm{~cm}^{3} / \Gamma, S_{\text {уд }}=158 \mathrm{~m}^{2} / \Gamma$. Промышленный силохром С-120 пропитывали раствором наногидрата нитрата алюминия, $\mathrm{Al}\left(\mathrm{NO}_{3}\right)_{3} \cdot 9 \mathrm{H}_{2} \mathrm{O}$, далее высушивали и прокаливали при $200^{\circ} \mathrm{C}$ в течение 2 -х часов. Приготовленный таким образом силохром с привитыми алюмосиликатными центрами (образец C-Al) содержит 1.65 мас\% $\mathrm{Al}_{2} \mathrm{O}_{3}$, или 2 мкмоль $\mathrm{Al} / \mathrm{M}^{2}$. Структурных характеристик исходного кремнезема модифицирование его поверхности алюминием практически не изменило: средний диаметр пор, d=200-300Å, суммарный объем пор $\mathrm{v}_{\Sigma}=1.1 \mathrm{~cm}^{3} / \Gamma, S_{\text {уд }}=160 \mathrm{~m}^{2} / \Gamma$.

Силохромы - гидрофильные сорбенты. Гидрофильность силохромам придают поверхностные группы $=\mathrm{Si}-\mathrm{OH}$, концентрация которых для полностью гидроксилированного аморфного кремнезема независимо от способа получения составляет $\sim 8$ мкмоль/м². Выделяют в основном два вида гидроксилов, различающихся по степени протонирования: кислотные парные соседние вицинальные, связанные водородными связями, и основные изолированные $[7,8]$. Кислотно -основное потенцио- 
метрическое титрование C-120 определило внутренний градиент кислотности гидроксилов в интервале $\mathrm{pH}=5-8$ [9]. Центрами специфической адсорбции являются кислотные парные гидроксилы и координационно ненасыщенные поверхностные атомы кремния. Когда на поверхности кремнезема при модифицировании часть атомов кремния замещается на атом трехвалентного, но четырех координационного атома алюминия, то происходит перераспределение электронной плотности. Трехзарядный ион алюминия на поверхности окружен тремя четырехзарядными ионами кремния, обладающими бо́льшей электроотрицательностью, 1.47 для Al и 1.74 для Si по Полингу. Это приводит к значительному понижению электронной плотности на атоме алюминия и, следовательно, к увеличению его электрофильности, Льюисовской кислотности. Молекулы воды подвергаются на поверхности алюмосиликата диссоциативной хемосорбции, что приводит к образованию сильного протонного кислотного центра Бренстеда, значительно превосходящие по своей каталитической и сорбционной активности протонные центры как силохрома, так и оксида алюминия. При нагревании до высокой температуры происходит обратная реакция: дегидратация поверхности и образование Льюисовского сильного кислотного центра [10].

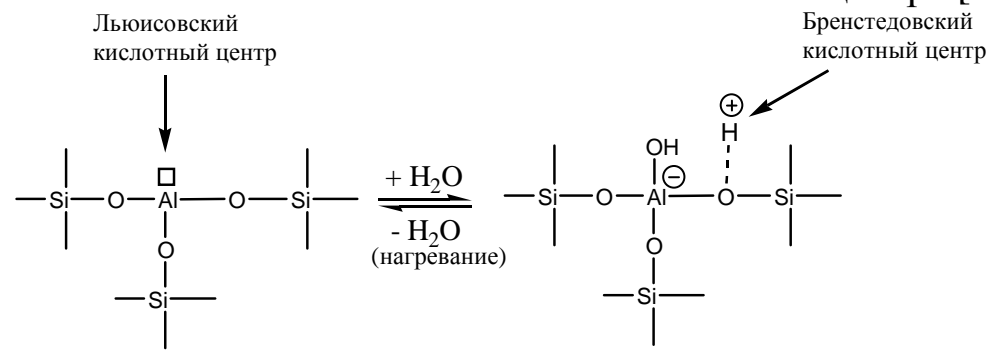

Приготовленный таким образом силохром с привитыми алюмосиликатными центрами (образец C-Al) может также содержать на поверхности помимо адсорбционных центров силикатной матрицы среднекислотные апротонные (льюисовские) и протонные (бренстедовские) центры дегидроксилированных и гидроксилированных участков оксида алюминия [10].
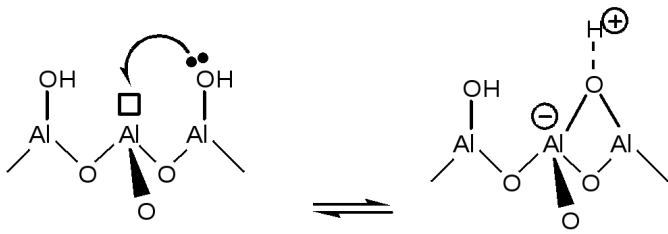

Путем ионного обмена на поверхность алюмосиликата C-Al и силохрома C120 наносили серебро. Для этого навески сорбентов сушили при $200^{\circ} \mathrm{C}$ на воздухе до постоянного веса для удаления сорбированной воды, заливали двукратным объемом 0.5 н раствора нитрата серебра, выдерживали в течение суток, сливали раствор, отмывали от нитрата серебра до слабокислой реакции и сушили при $\sim 100^{\circ} \mathrm{C}$. Так были приготовлены образцы C-Al- $\mathrm{Ag}^{+}$и $\mathrm{C}-\mathrm{Ag}^{+}$. Ионный обмен на структурных характеристиках сорбентов сказался в также пределах ошибки измерений, $\pm 3 \%$.

Чтобы оценить эффективность предлагаемого способа модифицирования поверхности адсорбента, сорбционные свойства кремнеземов $\mathrm{C}-\mathrm{Al}, \mathrm{C}-\mathrm{Ag}^{+}, \mathrm{C}-\mathrm{Al}^{-} \mathrm{Ag}^{+}$и исходного С-120, сравнивали со свойствами серебросодержащим кремнеземным C$3,2-\mathrm{Ag}^{0}$ и активированным кокосовым углем $\mathrm{AV}^{*}$. Образец C-3,2- $\mathrm{Ag}^{0}$ - силохром C120 , содержащий $3.2 \%$ мас металлического серебра в виде наночастиц со средним диаметром $\mathrm{d}=17.9$ нм, суммарный объем пор $\mathrm{v}_{\Sigma}=1.4 \mathrm{~cm}^{3} / \Gamma, S_{\text {уд }}=165 \mathrm{~m}^{2} / \Gamma[11,12]$. Согласно $[11,12]$, модифицирование гидратированной поверхности силохрома наночастицами серебра увеличивает ее гидрофильность за счет появления сильнокислотных центров Бренстеда в результате поляризации структурной и сорбированной воды наночастицами металла. Для дегидратированной поверхности серебросодержа- 
щего нанокомпозита на основе силохрома $[13,14]$, напротив, отмечено увеличение гидрофобности и сорбции неполярных веществ за счет того, что наночастицы серебра, как проводник, способны индуцировать диполь в молекулах веществ с высокой поляризуемостью [15].

Активированный кокосовый уголь $\mathrm{AУ}^{*}$ - умеренно гидрофильный, содержит серебро в форме наночастиц, диаметром с $\mathrm{d}=20.0$ нм. Серебро наносили на уголь пропиткой раствором нитратом серебра. Структурные характеристики образца; $\mathrm{S}_{\text {уд }}=1090 \mathrm{~m}^{2} / \Gamma$, из которых на макро - $(\mathrm{d}>100 \mathrm{Hм})$ и мезопоры $(5 \leq \mathrm{d} \leq 100$ нм $)$ приходится небольшая часть, $100 \mathrm{~m}^{2} / г$. Общий объем пор $\mathrm{v}_{\Sigma}=0.47 \mathrm{~cm}^{3} / \Gamma[2,3]$,

Удельную поверхность $\left(S_{\text {уд }}\right)$ образцов адсорбентов рассчитывали из низкотемпературных изотерм адсорбции азота, измеренных на адсорбционной вакуумной объемной установке [16]. Общий объем пор $\mathrm{v}_{\Sigma}$ определяли пропиткой водой до полного заполнения пор, определяемого по началу прилипания гранул к стенкам сосуда. Сорбционные свойства материалов изучали методом нелинейной газовой хроматографии [17].

Изучена сорбция веществ - возможных примесей в воде и веществ, моделирующих примеси, способных к различным видам межмолекулярных взаимодействий и индицирующих адсорбционные центры определенной природы (таблица 1).

Таблица 1. Характеристики адсорбатов - молекулярных зондов: молярная масса, $M$, температура кипения, $t_{\text {кип }}$ средняя молекулярная поляризуемость, $\alpha$, дипольный момент, $\mu$.

\begin{tabular}{|c|c|c|c|c|}
\hline Адсорбат & М, г/моль & $\mathrm{t}_{\text {кип }}{ }^{\circ} \mathrm{C}$ & $\alpha, \AA^{3}$ & $\mu$, Д \\
\hline $\mathrm{H}_{2} \mathrm{O}$ & 18 & 100 & 1.62 & 1.84 \\
\hline $\mathrm{CH}_{3} \mathrm{OH}$ & 32 & 64.5 & 4.3 & 1.70 \\
\hline $\mathrm{C}_{2} \mathrm{H}_{5} \mathrm{OH}$ & 46 & 78.4 & 5.6 & 1.68 \\
\hline $\mathrm{C}_{3} \mathrm{H}_{7} \mathrm{OH}$ & 60 & 117.5 & 9.5 & 1.63 \\
\hline $\mathrm{CCl}_{4}$ & 154 & 76.85 & 11.2 & 0 \\
\hline $\mathrm{CHCl}_{3}$ & 119,5 & 61.2 & 10.5 & 1.06 \\
\hline $\mathrm{C}_{6} \mathrm{H}_{6}$ & 78 & 80.1 & 10.4 & 0 \\
\hline $\mathrm{C}_{6} \mathrm{H}_{5} \mathrm{Cl}$ & 112,5 & 131 & 13.2 & 1.69 \\
\hline $\mathrm{C}_{6} \mathrm{H}_{5}-\mathrm{CH}-\left(\mathrm{CH}_{3}\right)_{2}$ & 120 & 152.39 & - & 2.85 \\
\hline $\mathrm{CH}_{3}-\mathrm{CO}-\mathrm{CH}_{3}$ & 58 & 56.1 & 6.6 & 0.85 \\
\hline$\left(\mathrm{C}_{2} \mathrm{H}_{5}\right)_{3} \mathrm{~N}$ & 101 & 89.5 & - & 0.66 \\
\hline $\mathrm{H}_{-}-\mathrm{C}_{6} \mathrm{H}_{14}$ & 86 & 68 & 11.9 & 0 \\
\hline
\end{tabular}

Для большинства молекулярных зондов в спектре элюативных кривых зависимость $h$ - $\tau$ (высота пика в максимуме - время удерживания, соответствующее максимуму) практически совпадала с тыловой ветвью, что позволяло вести расчет характеристик удерживания по одному пику. Из определенных в опыте базовых характеристик: концентрации сорбата в адсорбенте, $a$, соответствующего ей равновесного давления пара в газовой фазе, $p$, и удерживаемого объема, $V$, строили изотермы сорбции $a(p)$ и зависимости изостерических величин удерживаемого объема от степени заполнения поверхности адсорбента сорбатом, $V($ a). Изотермы и кривые $V(a)$ с хорошим приближением описывают полиномы 2-ой и 3-ей степени. Из них рассчитывали концентрации сорбата $a_{50}, a_{100}, a_{200}$ отнесенные к одному значению давления пара в газовой фазе $\mathrm{p}=50,100$ или 200мм.рт.ст., и изостерические величины удерживаемого объема сорбата $V_{1}, V_{5}, V_{10}$, и $V_{20}$, отнесенные к степени заполнения поверхности $\mathrm{a}=1,5,10$ или 20 мкмоль/г. Их использовали как меру емкости адсорбента по отношению к данному сорбату и меру активности сорбционного центра, меру сродства сорбента к данному сорбату (таблица 2). 
Таблица 2. Концентрации адсорбата на поверхности адсорбента $a(p)$, мкг/г, при фиксированных значениях давления пара $(p)$, мм.рт.ст. и значения изостерических величин удерживаемого объема $V_{\mathrm{a}}, \mathrm{cm}^{3} / \Gamma$ при фиксированных значениях $(a)$, мкмоль/г (по результатам газовой хроматографии).

\begin{tabular}{|c|c|c|c|c|c|c|c|}
\hline \multicolumn{2}{|c|}{$\underbrace{\text { адсорбент }}_{\text {адсорбат }}$} & C-120 & $\mathrm{C}-\mathrm{Ag}+$ & $\begin{array}{l}\mathrm{C}-3.2- \\
\mathrm{Ag}\end{array}$ & C-Al & $\begin{array}{l}\mathrm{C}-\mathrm{Al}- \\
\mathrm{Ag}+\end{array}$ & УA \\
\hline \multirow{2}{*}{ H. $\mathrm{C}_{6} \mathrm{H}_{14}$} & $a(200)$ & 690 & 580 & 490 & 1792 & 1370 & \\
\hline & $V(10)$ & 1.1 & 0.8 & 0.6 & 3.1 & 2.1 & \\
\hline \multirow{2}{*}{ C6H6 } & $a(50)$ & 300 & 320 & 300 & 1500 & 1060 & \\
\hline & $V(10$ & 2.0 & 1.4 & 1.9 & 10.9 & 7.4 & \\
\hline \multirow{2}{*}{$\mathrm{C}_{6} \mathrm{H}_{5} \mathrm{CH}\left(\mathrm{CH}_{3}\right)_{2}$} & $a(50)$ & & 2470 & & 5600 & 5000 & \\
\hline & $V(10)$ & & 11.2 & & 33.5 & 28.4 & \\
\hline \multirow{2}{*}{$\mathrm{C}_{6} \mathrm{H}_{5} \mathrm{Cl}$} & $a(50)$ & & 1280 & & 3200 & 2600 & \\
\hline & $V(10)$ & & 5.2 & & 18.0 & 15.1 & \\
\hline \multirow{2}{*}{$\mathrm{CHCL}_{3}$} & $a(100)$ & & 137 & & 1550 & 1335 & \\
\hline & $V(5)$ & & 0.8 & & 3.8 & 3.2 & \\
\hline \multirow{2}{*}{$\mathrm{CCl}_{4}$} & $a(100)$ & & 96.3 & & 1568 & 1480 & \\
\hline & $V(1)$ & & 1.2 & & 4.0 & 2.2 & \\
\hline \multirow{3}{*}{$\mathrm{CH}_{3} \mathrm{OH}$} & $a(50)$ & 139 & 377 & 360 & 1545 & 1650 & 1345 \\
\hline & $V(10)$ & 2.0 & 4.2 & 6.1 & 44.3 & 56.0 & 26.6 \\
\hline & $V(20)$ & 1.5 & 3.6 & 5.4 & 30.3 & 37.8 & 24.4 \\
\hline \multirow{2}{*}{$\mathrm{C}_{2} \mathrm{H}_{5} \mathrm{OH}$} & $a(50)$ & 390 & 620 & 870 & 1170 & 1950 & \\
\hline & $V(10)$ & 3.8 & 6.5 & 9.0 & 35.5 & 59 & \\
\hline \multirow{2}{*}{$\mathrm{H} 2 \mathrm{O}$} & $a(100)$ & 118 & 203 & 324 & 1470 & 1940 & 415 \\
\hline & $V(20)$ & 1.2 & 2.8 & 4.5 & 31.2 & 51.5 & \\
\hline \multirow{2}{*}{$(\mathrm{CH} 3) 2 \mathrm{CO}$} & $a(50)$ & & 1530 & & 2200 & 2500 & \\
\hline & $V(10)$ & & 16.0 & & 42.0 & 47.7 & \\
\hline
\end{tabular}

Хроматографические измерения проводили на газовом хроматографе ЛХМ$8 \mathrm{MД} \mathrm{с} \mathrm{детектором} \mathrm{по} \mathrm{теплопроводности} \mathrm{(катарометр),} \mathrm{ток} \mathrm{моста} \mathrm{-} 100$ ма при температуре опыта $180^{\circ} \mathrm{C}$. Скорость газа-носителя - гелия выбирали в интервале, в котором характеристики удерживания не зависели от расхода газа-носителя (35-45 $\mathrm{cm}^{3} /$ мин), что соответствует равновесной области процесса.

\section{Обсуждение результатов}

н-Гексан, моделирующий неполярные примеси, и неполярный тетрахлорметан, $\mathrm{CCl}_{4}$, сорбируются за счет неспецифических, дисперсионных, индукционных сил, величину которых определяет средняя молекулярная поляризуемость, $\alpha[6,7]$.

Исходный кремнезем C-120 в силу значительной гидрофильности неполярные вещества удерживает слабо. Модифицирование поверхности кремнезема наночастицами нульвалентного серебра (образец C-3,2- $\mathrm{Ag}^{0}$ ), снижает сорбцию неполярных веществ, что связано с увеличением ее гидрофильности [15]. Модифицирование поверхности силохрома ионами серебра (образец C-Ag+) вызывает такой же эффект, причем не только по характеру, но и по величине. Нанесение на поверхность С-120 алюмосиликатных групп (образец C-Al), напротив, вызывает заметный рост величин $a$ и $V$ неполярных веществ, что указывает на появление гидрофобных свойств. Замена части катионов водорода ионообменных центров этого образца на $\mathrm{Ag}^{+}$(образец C$\mathrm{Al}-\mathrm{Ag}+)$ несколько снижает гидрофобность поверхности - значения $a$ и $V$ неполярных сорбатов падают (рис.1а и б, таблица 2). 


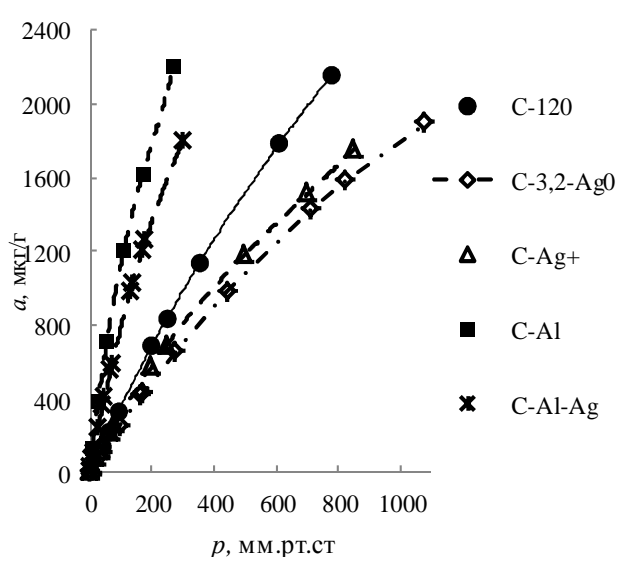

a

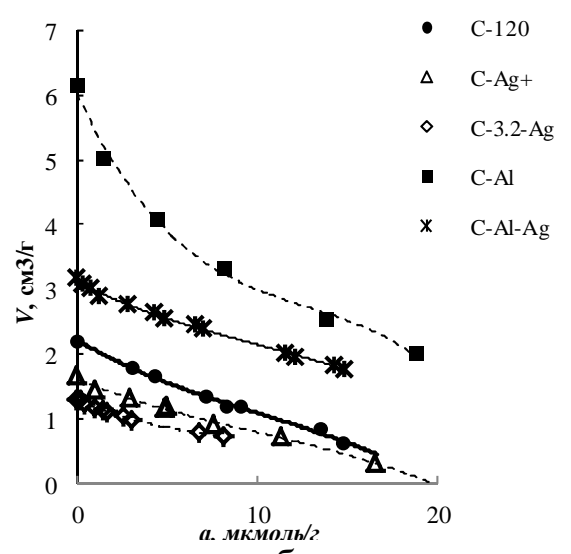

б

Рис. 1. а - изотермы сорбции н-гексана на модифицированных и исходном кремнеземах, б - зависимость $V(a)$ н-гексана на модифицированных и исходном кремнеземах

Ароматические углеводороды, бензол, кумол, хлорбензол, - носители высокой поляризуемости, $\alpha$, и квадрупольного момента, сорбируются за счет как специфических, так и неспецифических сил с преобладанием последних (таблица 1). Появление на поверхности силохрома C-120 серебра, как в форме наночастиц, так и в ионной форме (образцы C-3,2- $\mathrm{Ag}^{0}$ и $\mathrm{C}-\mathrm{Ag}^{+}$), несколько увеличивает сорбцию ароматических углеводородов и их галогенопроизводных за счет специфической составляющей по сравнению с исходным силохромом, причем сила эффектов модифицирования при условиях данного опыта сопоставима. Многократный рост как адсорбции, $a$, так и удерживаемого объема, $V$, ароматических углеводородов вызывает модифицирование поверхности силохрома алюмосиликатными центрами (образец C-Al). Модифицирование поверхности алюмосиликата серебром (образец C-Al-Ag+) несколько снижает сорбцию углеводородов и хлорорганики (рис. 2а и б, таблица 2), но при этом и емкость и активность адсорбента по отношению к этим веществам значительно превосходят эти характеристики, как исходного кремнезема, так и его серебросодержащих производных (рис. 2а и б, таблица 2).

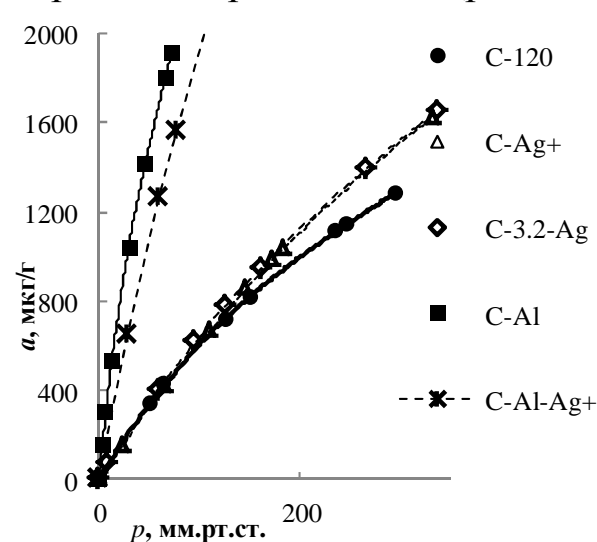

$\mathrm{a}$

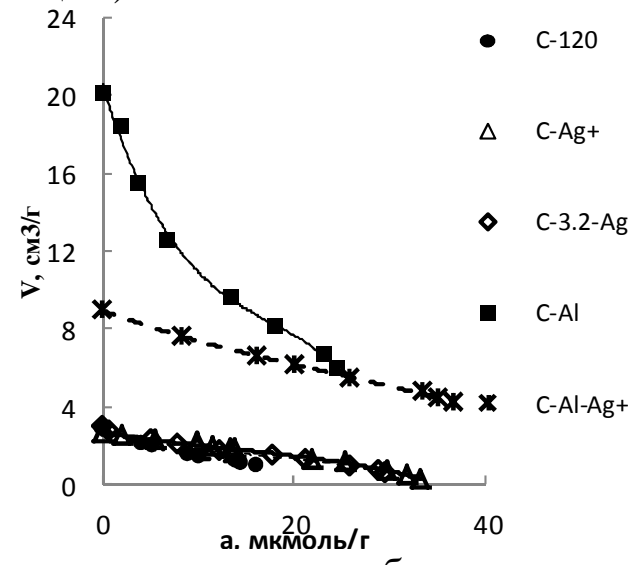

6

Рис. 2. а - изотермы сорбции бензола на модифицированных и исходном кремнеземах, б - зависимость $V(a)$ бензола на модифицированных и исходном кремнеземах

Хлороформ появляется в питьевой воде в результате хлорирования и присутствует в достаточно высоких концентрациях. $\mathrm{CHCl}_{3}$ относят к наиболее токсичным примесям, класс опасности - 2[1]. Как следует из таблицы 2, наиболее высокие ха- 
рактеристики удерживания по отношению к хлороформу проявил алюмосиликат С$\mathrm{Al}$, и появление на поверхности алюмосиликата ионов серебра (образец C-Al-Ag+) несколько снижает значения $a(100)$ и $V(5)$, что указывает на то, что хлороформ сорбируется преимущественно на гидрофобных участках поверхности. Хотя некоторое превышение сорбции слабо полярного $\mathrm{CHCl}_{3}$ по сравнению с неполярным $\mathrm{CCl}_{4}$ на кремнеземе $\mathrm{C}-\mathrm{Ag}+$ имело место.

Увеличение сорбции н-гексана, $\mathrm{CCL}_{4}, \mathrm{CHCl}_{3}$, ароматических углеводородов при модифицировании поверхности кремнезема алюминием (образец C-Al), указывает на то, что на его поверхности имеют место центры, способные к сильным неспецифическим взаимодействиям. Ими могут быть апротонные центры Льюиса. Для этих веществ, напр., для бензола, характерен вид зависимости $V(a)$ на C-Al: резкое падение кривой до а 20 мкмоль/г, до уровня значений $V$ для C-Al-Ag+ указывает на высокую неоднородность поверхности, присутствие на поверхности адсорбента активных центров разной природы и разной силы.

Спирты моделируют вещества, способные адсорбироваться за счет как специфических так и неспецифических сил с преобладанием специфических взаимодействий.

Вода, с ее незначительной поляризуемостью и значительным дипольным моментом (таблица 1), сорбируется, главным образом, за счет специфических водородных связей и является идеальным тестом на гидрофильность поверхности. Хотя, согласно [15], в газовой фазе в условиях опыта она присутствует в виде ассоциата из пяти молекул, который ведет себя как слабо полярное вещество с молярной массой 80 г/моль.

Модифицирование поверхности силохрома наночастицами серебра, образец $\mathrm{C}-3,2-\mathrm{Ag}^{0}$, значительно увеличивает гидрофильность поверхности, а, следовательно, и, адсорбцию воды и спиртов за счет появления на поверхности высокоактивных сорбционных центров - кислот Бренстеда, способных к сильным водородным и донорно-акцепторным связям [15].

Модифицирование поверхности силохрома С-120 катионами серебра (образец $\mathrm{C}-\mathrm{Ag}^{+}$), не смотря на незначительную обменную емкость силохрома, также заметно увеличивает сорбцию воды и спиртов по сравнению с исходной матрицей, при этом в очень узком интервале заполнения поверхности, для $a<2-3$ мкмоль/г, значения $V$ превосходят соответствующую характеристику этих сорбатов для серебросодержащего нанокомпозита, то есть на поверхности $\mathrm{C}-\mathrm{Ag}^{+}$присутствуют адсорбционные центры, превосходящие по способности к специфическим взаимодействиям адсорбционные центры C-3,2- $\mathrm{Ag}^{0}$ (рис. 3-4). При этом как сорбция, так и активность поверхности по отношению к специфически сорбирующимся веществам остаются ниже, чем для активированного угля.

Модифицирование поверхности силохрома алюмосиликатными центрами (образец $\mathrm{C}-\mathrm{Al}$ ) увеличивает как емкость образца, $a$, так и его сорбционную активность, $V$, по отношению к воде и спиртам по сравнению с углем и другими силохромами в несколько раз. Еще больше увеличивает сорбцию воды и спиртов модофицирование алюмосиликата серебром (образец C-Al- $\mathrm{Ag}^{+}$). Характер зависимости $V(a)$ для этих сорбатов - резкое падение удерживания с заполнением, очевидно указывает на энергетическую неоднородность сорбционных центров на поверхности этих образцов, и широкий качественный и количественный спектр этих центров. 

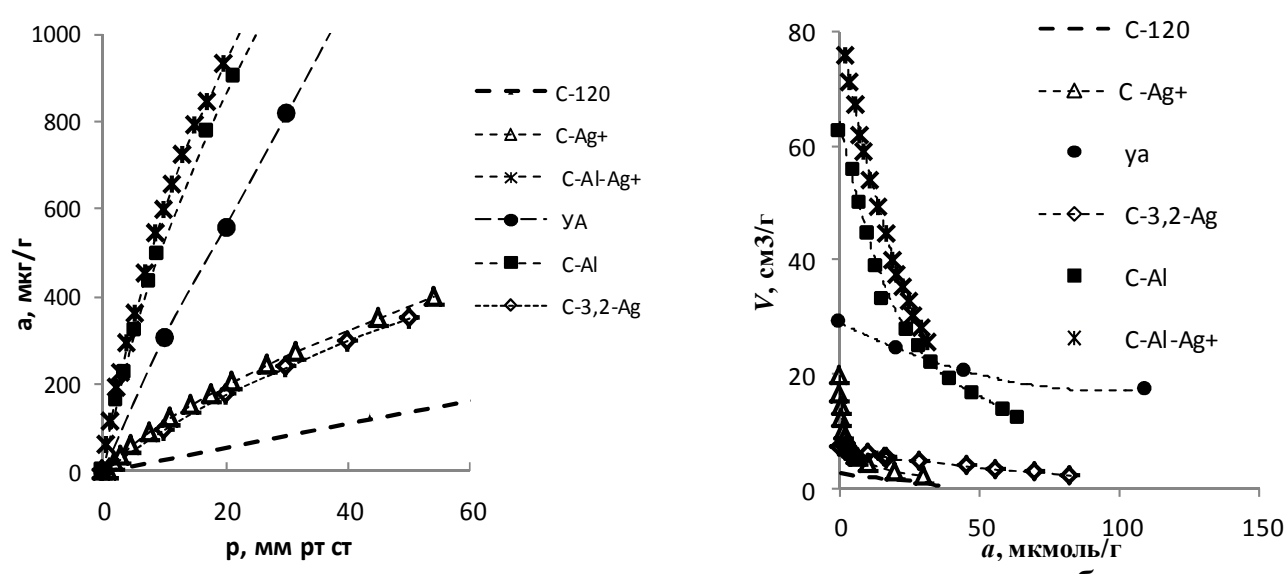

a

6

Рис. 3. а - изотермы сорбции метанола на кремнеземах C-120, C-Ag+, C-3.2$\mathrm{Ag}^{0}, \mathrm{C}-\mathrm{Al}, \mathrm{C}-\mathrm{Al}-\mathrm{Ag}+$ и активированном угле УА, б - зависимость $V(a)$ метанола на кремнеземах C-120, C-Ag+, C-3.2- $\mathrm{Ag}^{0}, \mathrm{C}-\mathrm{Al}, \mathrm{C}-\mathrm{Al}-\mathrm{Ag}+$ и активированном угле УА.
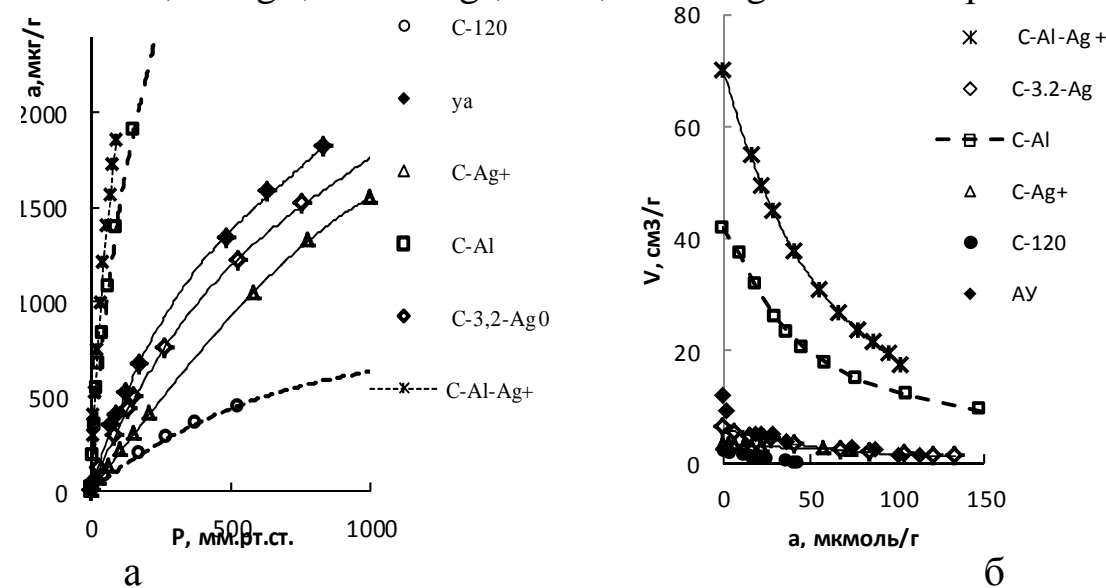

Рис. 4. а - изотермы сорбции воды на кремнеземах C-120, C-Ag+, C-3.2- $\mathrm{Ag}^{0}$, $\mathrm{C}-\mathrm{Al}, \mathrm{C}-\mathrm{Al}-\mathrm{Ag}+$ и активированном угле УА, 6 - зависимость $V(a)$ воды на кремнеземах C-120, C-Ag+, C-3.2- $\mathrm{Ag}^{0}, \mathrm{C}-\mathrm{Al}, \mathrm{C}-\mathrm{Al}-\mathrm{Ag}+$ и активированном угле УА.

Необходимо отметить, что все исследованные сорбаты, кроме н.гексана, сорбируются на C-Al сильнее воды (рис. 5). На образцах C-Ag+, C-Al и C-Al-Ag+ имело место частичное каталитическое превращения спиртов и ацетона. Триэтиламин (ТЭА), моделирующий аминокислоты, пептиды, белки, сорбируется на сильнокислотных протонных центрах с образованием солевой связи и на апротонных алюмосиликатных центрах, за счет донорно-акцепторной связи. Даже при столь высокой температуре опыта, $180^{\circ} \mathrm{C}$, образцы C-Ag+, C-Al и C-Al-Ag+ TЭА сорбируют необратимо. Проскок триэтиламина через колонку с силохромом, модифицированным катионами серебра (образец $\mathrm{C}-\mathrm{Ag}+$ ), имел место только после введения в колонку

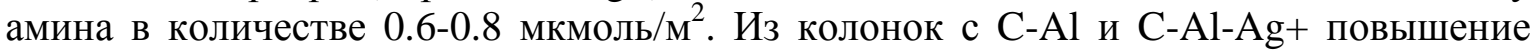
фонового уровня тока за счет вымывания амина, наблюдали после введения в колонки ТЭА в количестве 2-4 мкмоль/м². С увеличением концентрации ТЭА на поверхности кремнеземов наблюдали последовательное уменьшение удерживания, $V$, и сорбции, $a$, воды и спиртов. 


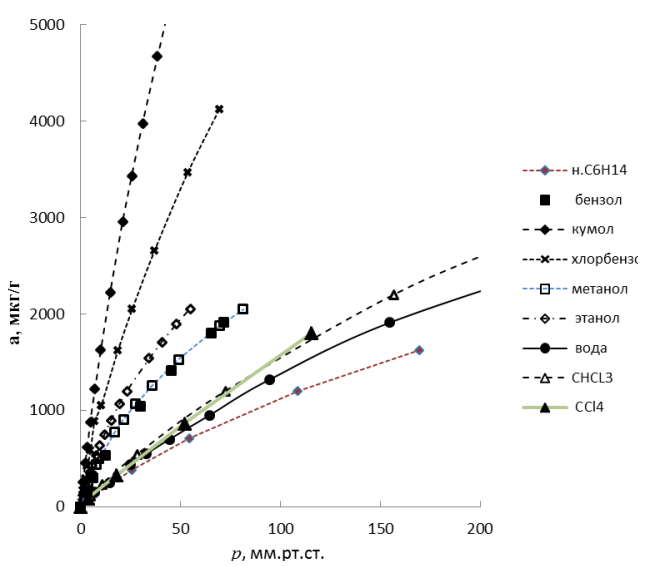

Рис. 5. Изотермы сорбции углеводородов, их хлори кислородпроизводных на алюмосиликате C-Al при $180^{\mathrm{j}} \mathrm{C}$

\section{Заключение}

Замена катионов водорода ионами серебра на поверхности силохрома вызывает увеличение гидрофильности, сорбции кислородсодержащих углеводородов, причем по силе этот эффект сопоставим с модифицированием поверхности наночастицами серебра. Модифицирование поверхности силохрома катионами алюминия вызывает многократное увеличение сорбции как специфически, так и неспецифически сорбирующихся веществ за счет появления на поверхности кислотных апротонных и протонных кислотных центров высокой и средней силы. Нанесение катионов серебра на поверхность силохрома, несущего алюмосиликатные комплексы, увеличивает ее гидрофильность, сорбцию спиртов, кетонов.

Знакопеременная поверхность таких сорбентов несет широкий спектр сорбционных центров разной природы и силы, что открывает возможность синтеза сорбентов узкоцелевого назначения. Такая поверхность проявляет способность к деструкции сорбированных веществ. Доказательство тому - различные каталитические превращения кислород содержащих органических веществ и ароматических углеводородов и денатурация белка в поверхностном слое [18]. Это обстоятельство может быть использовано при создании бактерицидных адсорбентов, альтернативных серебросодержащим.

\section{Список литературы}

1. ГОСТ 2874-82 Вода питьевая гигиенические требования и контроль за качеством. СанПиН 2.1.4.1116-02.

2. Котельникова Т.А., Кузнецов Б.В., Морева А.А. и др. // Сорбичонные и хроматографические проиессы. 2012. Т. 12. № 2. С. 295-303.

3. Котельникова Т.А., Кузнецов Б.В., Морева А.А. и др. // Сорбиионные и хроматографические проиессы. 2012. Т.12. № 4. С. 523-531.

4. Сертификат SUTCLIFFE SPEAKMAN CFRBONS LTD

5. Лурье А.А. Хроматографические материалы. М. Химия, 1978. С. 439.
6. Способ обеззараживания питьевой воды. Патент на изобретение №2381182. Золотухина Е.В., Кравченко Т.А., Ферапонтов Н.Б., Гриднева Е.В., Грабович М.Ю. Патентообладатель: Государственное образовательное учреждение высшего профессионального образования «Воронежский государственный университет» (RU). Дата регистрации: 21.04.2008. Номер заявки: 2008115682/15.

7. Грег С., Синг К. Адсорбция, удельная поверхность, пористость. Под ред. ч.-к. АН СССР Чмутова К.В. М. Мир. 1970. 255 с.

8. Киселев А.В., Лыгин В.И. Инфракрасные спектры поверхностных соединений. М. Наука. 1972. С. 403. 
9. Тессман А.Б., Иванов А.В, Вакштейн М.С. и др. // Вестн. Моск. Ун-та. Сер.2.Химия. 2002. Т. 43. № 1. С. 13-16.

10. Байгубекова Т.А, Киселев А.В., Никитин Ю.С. // Кинетика и катализ. 1972. Т. 13. Вып. 3. С. 755-761.

11. Котельникова Т.А., Кузнецов Б.В., Морева А.А. и др. // Журн. Физич. Химии. 2013. T. 87. № 8. C. 1379-1384.

12. Котельникова Т.А. // Журн. Физич. Химии. 2017. Том 91. № 7. С. 1193-1200.

13. Котельникова Т.А., Кузнецов Б.В., Муравьева Г.П. // Сорбционные и хроматографические прочессы. 2009. Т. 9. № 1. С. 147153.

\section{References}

1. GOST 2874-82 Voda pit'evaja gigienicheskie trebovanija i kontrol' za kachestvom. SanPiN 2.1.4.1116-02.

2. Kotel'nikova T.A., Kuznecov B.V., Moreva A.A. et al., Sorbtsionnye i khromatograficheskie protsessy, 2012, Vol. 12, No 2, pp. 295-303.

3. Kotel'nikova T.A., Kuznecov B.V., Moreva A.A. et al., Sorbtsionnye i khromatograficheskie protsessy, Vol. 12, No 4, pp. 523-531.

4. Sertifikat SUTCLIFFE SPEAKMAN CFRBONS LTD.

5. Lur'e A.A., Khromatograficheskie materialy, M., Himija, 1978, pp. 439.

6. Sposob obezzarazhivanija pit'evoj vody. Patent na izobretenie №2381182. Zolotuhina E.V., Kravchenko T.A., Ferapontov N.B., Gridneva E.V., Grabovich M.Ju. Patentoobladatel': Gosudarstvennoe obrazovatel'noe uchrezhdenie vysshego professional'nogo obrazovanija "Voronezhskij gosudarstvennyj universitet" (RU). Data registracii: 21.04.2008. Nomer zajavki: 2008115682/15.

7. Greg S., Sing K. Adsorbtsija, udel'naja povernost', poristost'. Pod red. ch.-k. AN SSSR Chmutova K.V., M., Mir, 1970, 255 p.

8. Kiselev A.V., Lygin V.I., Infrakrasnye spektry poverhnostnyh soedinenij, M., Nauka, 1972, pp. 403.

Котельникова Татьяна Александровна - к.Х.н., старший научный сотрудник, кафедра физической химии, химический факультет Московского государственного университета им. М.В.Ломоносова, Москва
14. Котельникова Т.А., Кузнецов Б.В., Муравьева Г.П. // Сорбиионные и хроматографические проиессы. 2009. Т. 9. № 3. С.399407.

15. Mignolet J.C.P. // J.Chem.Phys. 1953. Vol. 20. pp. 1298.

16. Экспериментальные методы в адсорбции и молекулярной хроматографии. Под ред. Ю.С. Никитина и Р.С. Петровой. М., Изд-во МГУ. 1990. С. 316.

17. Котельникова Т.А. // Журн. Физич. Химии. 2017. Т. 91. № 10. С. 1792-1798.

18. Wierenga P.A., Meinders M.B.J., Egmond M.R., et al. // J. Phys. Chem. B. 2005. Vol. 109. No 35. pp. 16946-16952.

9. Tessman A.B., Ivanov A.V, Vakshtejn M.S. et al., Vestn. Mosk. Un-ta. Ser.2.Himija, 2002, Vol. 43, No 1, pp. 13-16.

10. Bajgubekova T.A, Kiselev A.V., Nikitin Yu.S., Kinetika i kataliz, 1972, Vol. 13, No 3, pp. 755-761.

11. Kotel'nikova T.A., Kuznecov B.V., Moreva A.A. et al., Zhurn. Fizich. Himii, 2013, Vol. 87, No 8, pp. 1379-1384.

12. Kotel'nikova T.A., Zhurn. Fizich. Himii, 2017, Vol. 91, No 7, pp. 1193-1200.

13. Kotel'nikova T.A., Kuznecov B.V., Murav'eva G.P., Sorbtsionnye $i$ khromatograficheskie protsessy, 2009, Vol. 9, No 1, pp. 147153.

14. Kotel'nikova T.A., Kuznecov B.V., Murav'eva G.P., Sorbtsionnye $i$ khromatograficheskie protsessy, 2009, Vol. 9, No 3, pp. 399407.

15. Mignolet J.C.P., J.Chem.Phys., 1953, Vol. 20, pp. 1298.

16. Jeksperimental'nye metody $\mathrm{v}$ adsorbcii $\mathrm{i}$ molekuljarnoj hromatografii. Pod red. Ju.S. Nikitina i R.S. Petrovoj. M., Izd-vo MGU, 1990, pp. 316.

17. Kotel'nikova T.A., Zhurn. Fizich. Himii, 2017, Vol. 91, No 10, pp. 1792-1798.

18. Wierenga P.A., Meinders M.B.J., Egmond M.R. et al., J. Phys. Chem. B, 2005, Vol. 109, No 35, pp. 16946-16952.

Kotelnokova Tatyana A. - Cand.Chem.Sci., the senior scientific employee, faculty of physical chemistry, chemical faculty of the Moscow state university it M.V.Lomonosova, Moscow, takotelnikova@mail.ru 